\title{
The Assessment of the Training Process in Jordanian Hotels (A Field Study on Five-Star Hotels)
}

\author{
Mohammad S. Khasawneh ${ }^{1}$, Salem A. AL-Rahimy ${ }^{2}$ \& Hayel F. AL-Serhan ${ }^{2}$ \\ ${ }^{1}$ Tourism Management Department, Al-Balqa' Applied University, Jordan \\ ${ }^{2}$ Irbid National University, Jordan \\ Correspondence: Dr. Mohammad S. Khasawneh, Tourism Management Department, Al-Balqa' Applied \\ University, Jordan. E-mail: mohammadkassawnh28@yahoo.com
}

$\begin{array}{ll}\text { Received: February 20, } 2015 & \text { Accepted: March 20, } 2015 \quad \text { Online Published: March 28, } 2015 \\ \text { doi:10.5539/ijms.v7n2p104 } & \text { URL: http://dx.doi.org/10.5539/ijms.v7n2p104 }\end{array}$

\begin{abstract}
The study was aimed to identify the reality of the training process in Jordanian hotels classified as five-star category. Descriptive analytical method has been used and researchers have examined a random sample of employees in Jordanian hotels. The test contains lots of candidates come from 23 Jordanian hotels classified as five-star category. 281 questionnaires were distributed to employees. The study has pointed out that the Jordanian hotels are planning the training process well, and the hotels assess the training process in a suitable way to the employees' requirements, in addition, the hotels use effective training methods and carry on the assessment of the training process. The majority of the employees in Jordanian hotels are males.
\end{abstract}

Keywords: training, hotel, tourism, Jordan

\section{Introduction}

Nowadays, hotel industry is considered as one of the indispensable industries that forms tourism industry, recently hotel industry has been given much attention due to its important role in raising the economical growth. So, in order to achieve the prospective growth, paying attention to policies and strategies and the development of employees' performance in this sector are required to raise their compatibility.

Given that hotel sector in Jordan is one of the most distinguished sectors in tourism industry and witnesses a great competition from competitors like the international hotels in addition to costumer (tourist or resident) who need to be satisfied and his requirements need to be fulfilled, based on that, the assessment process of the employees working in hotel institutions within a certain norms becomes an inescapable postulate, specially institutions in the developed countries which evaluate performance steadily and continuously, if this approach is applied in the Jordanian foundation including hotel institutions, then these institutions can increase its compatibility, get the satisfaction of its customers, insure continuity and development, achieve profits and satisfaction and consequently and can achieve the objectives of the strategy.

\subsection{Significance of the Study}

The significance of this study comes from the following:

1) The significance of this study comes from the importance of tourism sector which includes the hotel-sector considered as an influential service sector in the world countries-economies like Jordan which is known as a poor-sources country, thus we should look for alternative resources that contribute in the development of the gross domestic product. So the suitable implementation to assess employees' performance will improve their performance and consequently the numbers of costumers will increase and their confidence in the Jordanian hotel institutions will also increase.

2) Getting benefit of the guidance rules provided by this research that could be used to improve hotel services.

3 ) Revealing the weak and strong points and the implemented methods in the assessment of the training process.

\subsection{Purposes of the Study}

This study is aiming to increase human resources performance levels working in the Jordanian hotel institutions and take the required procedures that enable them to use the available resources in the good manner to get their 
objectives affectively; the previous objectives can be accomplished through:

1) Recognizing the reality of planning for training in the Jordanian hotel institutions.

2) Recognizing the methods used in the assessment of training objectives in the Jordanian hotel institutions.

3) Knowing whether there is training-follow-up and evaluates its impact in the Jordanian hotel institutions.

4) Recognizing the impact of some variables on the training assessment process including scientific qualification, years of experience, job title and gender in the Jordanian hotel institutions.

\subsection{Problem Statement of the Study}

The main challenge of hotel sector in Jordan lies on employees' competence, their skills and qualification which can meet market requirements in the presence and in the future, so the hotels' top administrations tend to improve employees' performance throughout training and identifying accurately their training needs via adopting an affective evaluation system for training process which based on scientific indexes. Thus, this study will mainly focus on the investigation of "assessment of training process in the five-star hotel in Jordan by answering the following questions:

1) What is the reality of training planning in the Jordanian five-star hotels?

2) What is the evaluation of training objectives in the Jordanian five-star hotels?

3) Are there any training follow-up in the Jordanian five-star hotels?

4) Are there any evaluations for training impact in the Jordanian five-star hotels?

\subsection{Hypotheses of the Study}

The following hypotheses have been formulated:

(H1): the planning of the training process is fit from the Jordanian five-star employees' perspective.

(H2): the Jordanian five-star employees think that the design of the training program is suitable with their training needs.

(H3): employees of Jordanian five-star hotels think that the training methods used for training are effective.

(H4): employees of Jordanian five-star hotels think that hotels' top management support and interest in training process.

(H5): employees of Jordanian five-star hotels think that there is a continuous assessment for the training process.

\section{Previous Studies and Literature Review}

The researcher has reviewed the previous literature which addresses the subject of the study and found the following studies:

Al-Refaey \& Athary (2003): The aim of this study was to identify and illustrate the type of evaluation programs used in Kuwaiti institutions and show challenges facing these programs and how training could be developed? The sample of this study consisted of (51) Kuwaiti public institutions and was conducted among managers of training, human and administrative development. The results of the study showed that:

A. Questionnaire, performance record and observation were the most commonly used methods in evaluation of the training process.

B. The high-cost of the evaluation process and the suitable evaluation method that could be used for many training programs were the main challenges facing Kuwaiti organizations.

Al-Madhoon and Sadyyah (2006): Aimed at evaluating the training process of employees working in technical faculties in Gaza province from the perspective of trainees and trying to recognize their training needs. The population of this study consisted of all employees in six technical faculties, and the results were show the following:

A. There was a defect in identifying training needs, where no attention has been given to employees' job title, the results of performance evaluation, and the probability of transmitting or promoting the employees.

B. Faculties didn't follow policies that might encourage and enhance employees to take part in the training process.

C. The training process in higher-supervision faculties and faculties affiliated to

ANRWA were better developed than public-supervision faculties. 
The study recommended with the necessity of creating administration specialized in training and human development in the Ministry of higher education in order to improve employees in the technical faculties.

Badado (2006): The study aimed to explore the reality of human resources in the Jordanian tourism sector throughout concentrating on the economical and human factors of tourism development, and how to make harmony between the increasing tourist development and the limited human resources and to identify the problems facing tourist and hotel education. The results of the study showed:

A. A diversity of stuffs in charge of hotel and tourist education, the absence of coordination and the lack of reference has been found.

B. Unavailability of the scientific competences to perform training and education process in the tourism sector.

C. Hotel courses don't keep up with projects progress and labor market demands. According to the previous results the study recommended with the necessity of creating higher council for hotel training and instruction to embed policies and procedures of hotel education.

Junaidh (2001): This study aimed to recognize the costumers and government's impact on the evaluation of training process and to explore the need of customer for training, the sample of this study consists of many Malaysian institutions and the results of the study showed that:

A. An effect of Government and costumers on training evaluation has been found in terms of guiding training and access to the better results.

B. Practicing training evaluation has been widely criticized by costumers.

Mulder (2001): the study aimed to implement a special model of evaluation of training programs to enhance and improve the results of training programs evaluation. This model aims to identify the quality of training program in serving projects' managers, the results of the study showed that:

A. The results were convinced toward this model as it depends on affective bases.

B. This model was suitable for project aiming to accomplish an education results and changing work achievement successively.

\section{Methodology}

To accomplish the objective of this study, it has been divided into two parts:

1- Theoretical part: in this part the descriptive analytical approach for the references, journals and publications correspondent to the study has been used.

2- Field part: field survey method for employees working in the Jordanian five-star hotels has been used throughout questioner and statistical methods.

\subsection{Population and Sample}

The population of the study consists of Jordanian hotels classified as five-star with total number 23 hotels according to Ministry of Tourism statistics in 2012, distributed between Amman, Dead Sea, Aqaba and Petra. The sample of the study consists of employees in these hotels with various positions and job titles.

\section{Collecting Data}

\subsection{Instrument}

Questionnaire has been prepared for evaluating training process in the Jordanian hotels classified as five-stars hotels, which consisted of two parts: the first includes information correspondent to demographic features (gender, scientific qualification, years of experience and job title); the second includes items related to investigation subject aiming to evaluate training process in the Jordanian five-star hotel.

\subsection{Theoretical Frame}

\subsubsection{Training concept}

Training has been defined as a systematic process to change employees' behavior in order to develop organization's objectives at present and in the future. Also it was defined as the purposeful efforts aiming to provide individuals with information and knowledge that provide him with the required skills needed to perform work and develop his skills, knowledge and experiences that could double his competence (Al-Heety, 2005). Training is considered as one of the most essential activities that affects the human resources performance and it is not kind of wasting time as it was Believed, but it is related with the high quality in the organizations, since the continuity of organizations depends greatly on individuals' training and identifying their needs. 
For this reason, nowadays many organizations start paying attention to training so that they can develop human resources and provide this sector with knowledge and experiences required for developing their abilities. Recently, after the emergence of the term "intelligent principles" as it considered a new source of compatibility which is defined as the total of knowledge, skills and abilities that organization could have and direct these abilities toward production. Many firms started to adopt training programs attempting to construct their intelligent principles throughout knowledge administration activities in training and education (Dorah, 2003).

\subsubsection{Training Purposes}

Many organization's purposes could be achieved throughout training process implemented on the Jordanian hotels like:

1. The high of level productivity throughout the clarification of objectives, methods, procedures and helping employees to develop their skills (Barhoom \& Zaher, 2007).

2. Developing of services and goods presented to costumers which lead to the satisfaction of the costumer and enhancing hotels compatibility (Abbas, 2006).

3. Decreasing of errors and accidents levels at work which leads to high quality

product as a result of the good training applied on employees (Al-Daher, 2009).

4. Training enhances employees' self-confidence, self-reliance and self-respect in addition to raising employees' moral (Al-taany, 2003).

Additionally, as an essential component, training enables employees to transmit information to customers and clients (Mustafa, 2000), and it enables employees in solving problems that might face organizations.

\subsubsection{Concept of Training Evaluation}

Evaluation is known as the method of making judgment on certain elements like performance level, behavior and attitudes using certain norms to identify the competence of these elements (Al-ssen, 2005). Training evaluation means identifying whether training programs has accomplished its objectives or not according to training budget throughout measuring program's training revenue (Lesely, 2000). Also training is defined as a formal process based on scientific bases which are aiming to make accurate judgment on training system's components (Teresa et al., 2002). Therefore, in this study, training will be considered as "the procedures and methods used to measure training program's competence presented by Jordanian hotels, the probability of achieving the prospective objectives and the probable change made on hotels' employees"

4.2.4 The Purposes of Training Evaluation

Many people have believed that if there is a good training, it will be no need for making evaluation and follow-up procedures, which is a big mistake, since evaluation and following-up of the training activity is essential regardless with the availability of training plan. Thus, the purposes of training evaluation can be concluded as (Aqeely, 2008):

1. Realizing the fail or the success of training process and the reasons behind.

2. Knowing whether training process accomplish the prospective purposes.

3. Developing of the training process in the future and knowing the modifications needed to enhance training effectiveness.

4. Recognizing whether training process meet training needs or not.

5. Recognizing the training process ability of solving systematic problems and whether training has increased its effectiveness.

\subsection{Practical Frame}

\subsubsection{The Sample}

The questioner has been submitted to the sample of the study consisted of (281) employees, the number of employees who complete the questioner was (216) with average (76.86\%), while invalid questioners were (17) with average (6\%), and the questioners subjected to analysis were (199) with average (70.8\%) as shown in the table below. 
Table 1. The sample and responses

\begin{tabular}{lll}
\hline Inventory & Number & Percentage \\
\hline Distributed questioners & 281 & $100 \%$ \\
Recovered questioners & 216 & $76,86 \%$ \\
Invalid questioners & 17 & $6 \%$ \\
Questioners valid for analysis & 199 & $70,08 \%$ \\
\hline
\end{tabular}

Source: results of statistical analysis.

\subsubsection{Tool Reliability}

Cronbach Alpha for internal consistency has been used to test the reliability of participants' responses of the questioner's questions, the results was the following:

Table 2. Testing the reliability of study's tool

\begin{tabular}{lll}
\hline Item & Hypothesis & Alpha coefficient value \\
\hline Training process planning & $\mathrm{H}(1)$ & 0.874 \\
Training needs & $\mathrm{H}(2)$ & 0.692 \\
Training methods & $\mathrm{H}(3)$ & 0.792 \\
Top administration support & $\mathrm{H}(4)$ & 0.782 \\
Training evaluation & $\mathrm{H}(5)$ & 0.704 \\
\hline
\end{tabular}

Source: statistical analysis results.

Table 2 shows the test of tool reliability which approximate between $(69.2 \%-87.4 \%)$ which consider as statistically accepted reliability coefficient which means the probability of using the questioner in testing hypotheses.

Processing date related to respondents' demographic features

Demographic variables used are: gender, scientific qualification, years of experience and age. Table 3 illustrates the frequencies and percentage of each category.

Table 3. The description of demographic features

\begin{tabular}{llll}
\hline General info & inventory & Frequency & percentage \\
\hline Gender & Male & 144 & 72.36 \\
& female & 55 & 27.6 \\
\hline Scientific qualification & General secondary & 13 & 6.53 \\
& Diploma & 80 & 40.20 \\
& Bachelor & 100 & 50.25 \\
& Higher education & 6 & 3.01 \\
\hline Age & Less than 30 years & 43 & 21.6 \\
& 30-less than 40 & 99 & 49.7 \\
& 40-less than 50 & 45 & 22.6 \\
& 50-less than 60 & 8 & 4.02 \\
\hline Years of experience & Less than 5 years & 45 & 22.6 \\
& 5-less than 10 years & 50 & 25.1 \\
& 10-less than 15 years & 70 & 35.2 \\
& More than 15 years & 34 & 17.1 \\
\hline
\end{tabular}

As shown in table 3 the rate of male in hotel sector was high, while female ratio was low with 27.6 which indicate that Jordanian women involve less in this kind of work, and this probably due to social restrictions and the prevalence of flaw culture. Employees who has bachelor degree come first with average $50.2 \%$ while employees with higher education come last with average $3.01 \%$ which probably due to the chance of this category to have a better paid-job or having job in this sector requires a certain conditions. Age category (30-less than 40 years) at first rank with average 49.7 , while age category (50-less than 60 years) at last with average $4.2 \%$ which indicate that Jordanian hotels attracts young people and hotels works requires physical abilities, 
while the category (10-less than 15 years experience) at first with average 35.25 , then category described (5-10 years experience) come secondly with average $25.1 \%$, and at

last comes the category having more than 15 years of experience with average $7,1 \%$ and that is probably because these hotels has been recently constructed, thus these hotels depends on young people in the beginning.

\subsubsection{Testing Hypotheses}

$\mathrm{H}(1)$ : the planning of the training process is fit from the perspective of Jordanian five-star employees. For the investigation of this hypothesis, the averages and standerd deviations for each item of evaluation of training process, were calculated the as shown below:

Table 4. The first hypothesis's responses

\begin{tabular}{lllll}
\hline Num & Item & average & SD & rank \\
\hline 1 & There is a yearly systematic plan at the level of the hotel & 3.7286 & 0.94641 & 7 \\
2 & Training plan based on employees' training needs & 4.0553 & 0.84803 & 1 \\
3 & Employees share in the planning of the training process & 3.7789 & 0.92188 & 5 \\
4 & The duration of training program id fit for training category & 3.7739 & 0.91238 & 6 \\
5 & Administrations and departments acquaint the training plan of its employees & 3.9095 & 0.85980 & 3 \\
6 & The place in which the training program is held is fit & 3.7136 & 0.91749 & 8 \\
7 & Training plan abide the suitable time for trainees & 3.8995 & 0.82874 & 4 \\
8 & Training material related to the prospective objectives of the program & 3.9296 & 0.90736 & 2 \\
9 & There is a continuous frequency of the program's content & 3.7035 & 1.01878 & 9 \\
10 & Personal relation interfere with the employees' participation in the training & 3.5779 & 0.76720 & 10 \\
\hline
\end{tabular}

Source: the results of the statistical analysis.

As shown in table above we can notice the field of evaluation of planning of training process in the Jordanian hotel classified as five-star hotel, the item (Training plan based on employees' training needs) comes first with average (4.0553) which indicate to hotel's interest in investigation of employees' training needs. Then the item (Training material related to the prospective objectives of the program) comes in the second rank with average (3.9296) which indicate that there is a compatibility between the training programs presented by Jordanian hotels and the programs' objectives, while item five (Administrations and departments acquaint the training plan of its employees) comes next with average (3.9095) indicating that hotels' administrations and departments are sharing the setting up of the training plan in the hotel, item seven (Training plan abides the suitable time for trainees) comes next with average (3.8995) indicating to the trainees' comfort toward training times, while the item (There is a yearly systematic plan at the level of the hotel) comes in the seventh rank with average (3.7286) indicating that employees may not aware of training plans.

Item number 9 comes penultimate with average (3.5779) which indicate that hotel attempt to have modern and renewable training programs, item number 10 (Personal relations interfere with the employees' participation in the training) comes last with average (3.5779) as an indication that hotel's fair in sharing all employees in the training programs. The total level of planning evaluation for training process in the Jordanian hotels classified as five-star hotel was high with mean (3.8920) indicating that the level of planning evaluation of training was high in the five-star hotels. As mentioned above we can notice that planning evaluation of training process was high. The results of T-Test are shown in the following table.

Table 5. One-sample test

\begin{tabular}{|c|c|c|c|c|}
\hline Num & Item & average & $\mathrm{SD}$ & rank \\
\hline 1 & There is a yearly systematic plan at the level of the hotel & 3.7286 & 0.94641 & 7 \\
\hline 2 & Training plan based on employees' training needs & 4.0553 & 0.84803 & 1 \\
\hline 3 & Employees share in the planning of the training process & 3.7789 & 0.92188 & 5 \\
\hline 4 & The duration of training program id fit for training category & 3.7739 & 0.91238 & 6 \\
\hline 5 & Administrations and departments acquaint the training plan of its employees & 3.9095 & 0.85980 & 3 \\
\hline 6 & The place in which the training program is held is fit & 3.7136 & 0.91749 & 8 \\
\hline 7 & Training plan abide the suitable time for trainees & 3.8995 & 0.82874 & 4 \\
\hline 8 & Training material related to the prospective objectives of the program & 3.9296 & 0.90736 & 2 \\
\hline 9 & There is a continuous frequency of the program's content & 3.7035 & 1.01878 & 9 \\
\hline 10 & Personal relation interfere with the employees' participation in the training & 3.5779 & 0.76720 & 10 \\
\hline
\end{tabular}

Source: statistical analysis results. 
T-test has been used, and the finding of the statistical analysis shows the value of significance $(\alpha=0.000)$ and the value of $\mathrm{T}=16.270$ indicate significantly on the point $(\alpha \leq 0.05)$ which means the acceptance of the Hypothesis (1).

$\mathrm{H}(2)$ : The Jordanian five-star employees think that the design of the training program is suitable with their training needs.

As shown in the table 6, averages have been used to test the second hypothesis.

Table 6. Second hypothesis' responds

\begin{tabular}{|c|c|c|c|c|}
\hline Number & Item & Average & SD & Rank \\
\hline 1 & Training program is designed according to employees' training needs & 4.1658 & 75051 & 3 \\
\hline 2 & The identified Training needs meets employees' training needs & 4.1657 & 67990 & 4 \\
\hline 3 & Training needs identification based on measurable real norms & 4.1256 & 85829 & 6 \\
\hline 4 & Training process designed according to employees' specialization & 4.2211 & 74627 & 1 \\
\hline 5 & training needs are identified before designing training programs & 4.1407 & 77896 & 5 \\
\hline 6 & Training objectives fit with job requirements & 4.2161 & 61.14 & 2 \\
\hline 7 & Training program is designed according to tourism market need & 4.0000 & 75210 & 9 \\
\hline 8 & $\begin{array}{l}\text { Tourism program design fits Jordanian strategy for tourism } \\
\text { development }\end{array}$ & 3.8543 & 87840 & 10 \\
\hline 9 & $\begin{array}{l}\text { Training program is designed according to periodical evaluation for } \\
\text { employees' performance }\end{array}$ & 4.0653 & 79820 & 7 \\
\hline 10 & Training program design comply with future training needs & 4.0151 & 74858 & 8 \\
\hline Total & & 4.1935 & 63684 & \\
\hline
\end{tabular}

Source: statistical analysis results.

The previous table shows the field of identification of training needs in the Jordanian five-star hotels, however, item 4 (Training process designed according to employees' specialization) comes first with average (4.1935) which indicate that hotel interest in employees' specialization when identify their training needs, item 6 (Training objectives fit with job requirements) comes secondly with average (4.2161) indicating to a strong relation between training program objectives and employees' job. While item 1(Training program is designed according to employees' training needs) comes third with average (4.1658) which indicate to the training plan interest in employees' training needs. Item 7 (Training program is designed according to tourism market needs) comes penultimate with average (4.0000) which indicate that hotel does not pay attention to tourism market's need and the lack of studies dealing with this field. Item 8 (Tourism program design fits Jordanian strategy for tourism development) comes last with average (3.8543) indicating to the lack of coordination between Jordanian hotels and Jordan Tourism Board relating with employees training.

The total level of training needs identification field in the Jordanian five-star hotels was high and the average of individuals estimation was (4.1935) which is bigger than the hypothetical average of measure tool (3), the standard deviation was (0.63684) indicating to the consistence of responds which indicate to the interest of training needs identification and that identification is based on the measurable trainees needs.

Table 7. One-sample test

\begin{tabular}{|c|c|c|c|c|c|c|}
\hline \multirow[t]{4}{*}{ Training needs } & \multicolumn{6}{|c|}{ Test Value $=3$} \\
\hline & \multirow[t]{2}{*}{$\mathrm{T}$} & \multirow[t]{2}{*}{$\mathrm{DF}$} & \multirow[t]{2}{*}{$\begin{array}{l}\text { Sig } \\
\text { (2-tailed) }\end{array}$} & \multirow[t]{2}{*}{ Mean difference } & \multicolumn{2}{|c|}{$\begin{array}{l}95 \% \text { confidence interval of the } \\
\text { difference }\end{array}$} \\
\hline & & & & & Lower & Upper \\
\hline & 26.437 & 198 & 0.000 & 1.19347 & 1.1044 & 1.2825 \\
\hline
\end{tabular}

Source: statistical analysis results.

T-test has been used, and the finding of the statistical analysis shows the value of significance $(\alpha=0.000)$ and the value of $\mathrm{T}=26.437$ indicate significantly on the point $(\alpha \leq 0.05)$ which means the acceptance of the Hypothesis (2).

H(3): Jordanian five-star hotels employees think that the training methods used for training are effective. 
As shown in the table below, averages and standard deviations have been calculated for each items of the field to test the validity of the third hypothesis.

Table 8. Third hypothesis' responds

\begin{tabular}{lllll}
\hline Num & Item & average & SD & Rank \\
\hline 1 & Training methods develop trainees' creative skills & 3.7286 & 0.94641 & 7 \\
2 & Training methods contribute in trainees interaction with trainer & 3.9296 & 0.90736 & 2 \\
3 & Training methods make content realized by trainees & 3.7789 & 0.92188 & 5 \\
4 & Training methods help in the quick understanding of information & 3.7739 & 0.91238 & 6 \\
5 & Training methods develop cooperative work with trainer & 3.9095 & 0.85980 & 3 \\
6 & Training methods increase employees' self-confidence & 3.7136 & 0.91749 & 8 \\
7 & Training methods develop employees' co-working and team spirit & 4.0553 & 0.84803 & 1 \\
8 & Training methods save trainees efforts & 3.5779 & 0.076720 & 10 \\
9 & Training methods change the role of trainer as a participant in & & & \\
& training process & & & \\
\hline & Total & 3.8945 & 9.65994 & \\
\hline
\end{tabular}

Source: statistical analysis results.

As shown in the table above, we can notice the average of sample-individuals estimations was (3.8945) which Is parallel to the high acceptance level and it is higher than the hypothetical average of the measure tool (3), responds' standard deviation in this field was (0.65994) indicating to the consistence of responds and the agreement of samples individuals for the validity of these questions. However, item 7 (Training methods develop employees' co-working and team spirit) comes first which means that training method enhances cooperative work and team spirit, while item 2 (Training methods contribute in trainees interaction with trainer) comes secondly, item 8 (Training methods save trainees efforts) comes last which indicate that training method selection does not pay any attention to the exerted trainees' effort.

Table 9. the results of one-sample test

\begin{tabular}{lllllll}
\hline \multirow{2}{*}{$\begin{array}{l}\text { Training } \\
\text { effectiveness }\end{array}$} & methods & \multicolumn{2}{l}{ Test Value=3 } & & & \\
\cline { 2 - 7 } & $\mathrm{T}$ & DF & \multirow{2}{*}{$\begin{array}{l}\text { Sig } \\
(2 \text {-tailed })\end{array}$} & & Mean difference & \multicolumn{2}{l}{$\begin{array}{l}\text { 95\% confidence interval of the } \\
\text { difference }\end{array}$} \\
\cline { 3 - 7 } & & & & & Lower & Upper \\
\cline { 2 - 7 } & 14.151 & 108 & 0.000 & 0.89450 & 0.7692 & 1.0198 \\
\hline
\end{tabular}

Source: statistical analysis results.

T-test has been used, and the finding of the statistical analysis shows the value of significance $(\alpha=0.000)$ and the value of $T=14.151$ indicate significantly on the point $(\alpha \leq 0.05)$ which means the acceptance of the Hypothesis (3).

H(4): Jordanian five-star hotels employees think that hotels' top administrations support and interest in training process. As shown in the table 9, averages and standard deviations have been inferred for each items of the field to test the validity of the fourth hypothesis. As shown in the table, we can notice that the average of sample-individuals estimations was (3.7437) which is parallel to the high consistence, also it is higher than the hypothetical average of measure tool (3), the standard deviation of responds in this field was (0.72798) which indicate to the consistence of responds and the agreement of sample individuals with the validity of these questions. However, item 4 (Hotel administration promotes distinguished trainees) comes first which indicate that hotel administration interests in distinguished employees during training, while item 1 (At the hotel, there is a private administration specialized in training and developing human resources) comes in the second rank which reflexes the hotel administration's interest in training, item 6 (Hotel administration allocates funds required for training) comes last because of the lack of knowledge in this side. 
Table 10. Illustrate the results of hypothesis 4 responds

\begin{tabular}{lllll}
\hline Num & Item & average & SD & rank \\
\hline 1 & At the hotel, there is a private administration specialized in training and & 4.0402 & 0.75772 & 2 \\
& developing human resources & & & 5 \\
2 & Hotel administration attempts to join all employees in training process & 3.8392 & 0.83137 & 5 \\
3 & Hotel administration encourages employees to enroll in training programs & 3.8643 & 0.76981 & 4 \\
4 & Hotel administration promotes distinguished trainees & 4.2160 & 0.70963 & 1 \\
5 & Hotel administration assesses training process & 3.8945 & 0.96605 & 3 \\
6 & Hotel administration allocates funds required for training & 3.6231 & 0.9960 & 6 \\
\hline & Total & 3.7437 & 0.72798 & \\
\hline
\end{tabular}

Source: statistical analysis results.

T-test has been used, and the finding of the statistical analysis shows the value of significance $(\alpha=0.000)$ and the value of $T=14.412$ indicate significantly on the point $(\alpha \leq 0$. 05) which means the acceptance of the Hypothesis (4) stating that Jordanian five-star top administration supports training process.

Table 11. One-sample test results

\begin{tabular}{|c|c|c|c|c|c|c|c|}
\hline \multirow{4}{*}{$\begin{array}{l}\text { Top } \\
\text { support }\end{array}$} & \multirow[t]{4}{*}{ administration } & \multicolumn{6}{|c|}{ Test Value $=3$} \\
\hline & & \multirow[t]{2}{*}{$\mathrm{T}$} & \multirow[t]{2}{*}{ DF } & \multirow[t]{2}{*}{$\begin{array}{l}\text { Sig } \\
\text { (2-tailed) }\end{array}$} & \multirow[t]{2}{*}{ Mean difference } & \multicolumn{2}{|c|}{$\begin{array}{l}95 \% \text { confidence interval of the } \\
\text { difference }\end{array}$} \\
\hline & & & & & & Lower & Upper \\
\hline & & 14,151 & 108 & 0,000 & 0,89450 & 0,7692 & 1,0198 \\
\hline
\end{tabular}

Source: statistical analysis results.

$\mathrm{H}(5)$ : Jordanian five-star hotels employees think that there is a continuous assessment for the training process.

As shown in the table 12, averages and standard deviations have been inferred for each items of the field to test the validity of the fifth hypothesis.

Table 12. Illustrate the results of hypothesis 5 responds

\begin{tabular}{lllll}
\hline Num & Item & Average & SD & rank \\
\hline 1 & assessment methods used in training fulfills training objectives & 3.7236 & 0.73079 & 6 \\
2 & Hotel is often in contact with training side before and after training. & 3.7839 & 0.84599 & 5 \\
3 & During training, There is a balance between theoretical and practical activities & 3.8794 & 0.81373 & 3 \\
4 & Training instruments used in training appropriate with training nature & 3.8744 & 0.82223 & 4 \\
5 & Training received fits with my job & 3.8945 & 0.87266 & 1 \\
6 & Hotel administration interests in training I received & 3.8794 & 0.90203 & 2 \\
\hline & Total & 3.8090 & 73079 & \\
\hline
\end{tabular}

Source: statistical analysis results.

As shown in the table, and through data of evaluation of training process in the Jordanian five-star hotel, we notice that item 5 (Training received fits with my job)comes first with average (3.8945) which indicate to the hotel's interest of the selection of training program quality that fit with employees' job nature, then item 6 (Hotel administration interests in training I received) secondly with average (3.7894) which is apparently index that hotel consider training as essential not just applied program, while item 1(assessment methods used in training fulfills training objectives) comes last with average (3.7236) and this is probably due to employees' unawareness of evaluation methods used in training process. The average of sample-individuals estimations was (3.8090) which is parallel to the high consistence level, also it is higher than the hypothetical average of measure tool (3), the standard deviation of responds in this field was (73079) which indicates to the consistence of responds and the agreement of sample individuals with the validity of these question and prove the continuous evaluation of training process performed by the Jordanian five-star hotels. 
Table 13. The one-sample test results

\begin{tabular}{|c|c|c|c|c|c|c|}
\hline \multirow{4}{*}{ Training evaluation } & \multicolumn{6}{|c|}{ Test Value $=3$} \\
\hline & \multirow[t]{2}{*}{$\mathrm{T}$} & \multirow[t]{2}{*}{ DF } & \multirow[t]{2}{*}{$\begin{array}{l}\text { Sig } \\
\text { (2-tailed) }\end{array}$} & \multirow[t]{2}{*}{ Mean difference } & \multicolumn{2}{|c|}{$\begin{array}{l}95 \% \text { confidence interval of the } \\
\text { difference }\end{array}$} \\
\hline & & & & & Lower & Upper \\
\hline & 15.617 & 198 & 0.000 & 80905 & 0.9112 & 0.7069 \\
\hline
\end{tabular}

Source: statistical analysis results.

T-test has been used, and the finding of the statistical analysis shows the value of significance $(\alpha=0.000)$ and the value of $T=15.617$ indicate significantly on the point $(\alpha \leq 0.05)$ which means the acceptance of the Hypothesis (5) stating that there Is a continuous assessment of training process in the Jordanian five-star hotels.

\section{Conclusions}

Based on the study's analysis the following results have been found:

1. The 30-40 years old category is the main category involved in this kind of work, and their years of experience were between 10-less than 25years.

2. Low number of females involved in this kind of work has been found.

3. Bachelor degree is the common degree among those who are working in the Jordanian hotels, and Diploma comes secondly, whereas apparently low number of employees with higher education has been found.

4. A suitable planning for training process has been found in the Jordanian hotels and the plan is base on employees' training needs, and usually linked with prospective objectives, whereas no yearly training plan on the level of the hotel has been found.

5. Training programs design is based on the identification of training needs and according to employees' specialization and their jobs requirements, but this programs are not evaluated in line with the local strategy for tourism development and according to the tourism market need.

6. Training methods are effective and develop cooperative work and team spirit and leads to the interaction between trainer and trainee but these methods don't save trainees' efforts.

7. Top administration of Jordanian five-star hotels support training process, promotes distinguished trainees, and it has a specialized training administration whereas it does not allocate certain funds for training process.

8. The study shows that there is a continuous assessment for the training process in the Jordanian five-star hotels, and training received by trainees is appropriate with his job, also hotel top administration interests in training evaluation but evaluation methods used don't verify training objectives.

\section{Recommendations}

Based on the results, the following recommendations have been concluded:

1. People shall be encouraged to practice working in hotels sector kind of work and higher education graduate shall be encouraged to work in the Jordanian hotels.

2. Awareness programs shall be done to encourage females to work in hotel sector.

3. Training programs shall be designed appropriately with the national strategy for tourism development and according to the need of the Jordanian tourism market throughout the coordination with Jordan Tourism Board.

4. Certain funds of hotels' budget shall be allocated for training process.

5. Methods used in training shall be reconsidered in which it can accomplish training objectives.

6. Effective training methods shall be selected in which it can save trainees' efforts.

7. A yearly training plan regard to the hotel shall be established.

\section{References}

Abbas, S. (2006). Human resource strategic introduction (2nd ed.). Amman: Dar Wael for publication and distribution.

Al-Daher, N. I. (2009). Human resource development (1st ed.). Irbid: Modern Book World.

Al-Heety, K. A.-R. (2005). Human resources Management (2nd ed.). Amman Dar Wael for publication and distribution. 
Al-Madhoon, M., \& Saddyyah, M. (2006). The reality of training needs planning in Gaza provinces trainees' perspective. Development of Gaza strip conference after Israeli withdrawing, 13-15 April, Gaza strip.

Al-Refaey, H., \& Al-Athary, A. (2002). Training evaluation theory and application. Arab Education Future Journal, 9, 152.

Al-ssen, A.-A. (2005). Evaluation of training process effectiveness and the implementation of training economies principle. Conference of training and consultancies, 5-8 June, Arab organization for administrative development, Beirut, Lebanon.

Al-taany, H. (2003). Training concept and constructing training programs. Amman: Dar Al-Shoroq for publication and distribution.

Aqeely, O. W. (2008). Modern human resources management as a strategic dimension. Dar Wael for Publishing and distribution, 2009, Amman.

Badado, I. (2006). Human resources evaluation in the Jordanian Tourism sector. Conference of tourism economies: reality and hope, Al-Hashemite University, October, Zarqa, Jordan.

Barhoom, A., \& Zaher, B. (2007). Training impact on health service quality improvement in the Ministry of Higher Education Hospitals empirical study in Al- Assad University Hospital in lataqia. Teshreen University for researches and studies Journal, economic and legal sciences, 9(2), 207.

Brannick, T., de Burca, S., \& Fynese. (2002). Service Management Practice-Performance. Model: a focus on Training Practice. Journal of European Industrial Training, 26(8), 394-403. http://dx.doi.org/10.1108/03090590210444973

Dorah, A.-B. I. (2003). Organization's Human performance technology, theoretical principles and its significance in Arab Environment. Arab organization for administrative development, Egypt.

Jundiah, H. (2001). Training Evaluation, Clients Roles. Journal of European Industrial Training, 25(7), 374-379. http://dx.doi.org/10.1108/EUM0000000005838

Lesely, R. (2000). Measurement of training effectiveness. Translated by Hamza Sir- Elkhatim, general management institution, Kingdomof Saudi Arabia.

Mahfood, A. J. (2001). Training needs identification and the impact on the comprehensive quality. Unpublished Doctorate dissertation, economic sciences faculty, Algeria University.

Mulder, M. (2001). Customers Satisfaction with Training Programs. Journal of European Industrial Training, 25(6), 321-331. http://dx.doi.org/10.1108/03090590110401791

Mustafa, A. S. (2000). Human resource Management the twenty first century's perspective. Cairo: Anglo Egyptian Library.

\section{Copyrights}

Copyright for this article is retained by the author(s), with first publication rights granted to the journal.

This is an open-access article distributed under the terms and conditions of the Creative Commons Attribution license (http://creativecommons.org/licenses/by/3.0/). 